Celgene, Genentech, GSK, Janssen, Eli Lilly and Company, Pfizer, Sanofi-Aventis, UCB, P. Emery Consultant for: Pfizer, MSD, Abbvie, BMS, UCB, Roche, Novartis, Samsung, Sandoz, Eli Lilly and Company

DOI: 10.1136/annrheumdis-2018-eular.1995

\section{AB0259 CLINICAL MANAGEMENT OF SERONEGATIVE AND SEROPOSITIVE RHEUMATOID ARTHRITIS: A COMPARATIVE STUDY}

K. Lee ${ }^{1}$, S.-T. Choi ${ }^{2} .{ }^{1}$ Dongguk University Ilsan Hospital, Goyang; ${ }^{2}$ Chung-Ang University College of Medicine, Seoul, Korea, Republic of Ireland

Background: Both rheumatoid factor (RF) and anti-cyclic citrullinated peptide antibody (ACPA) are associated with poor radiologic outcomes in patients with rheumatoid arthritis (RA). In general, RA patients positive for RF or ACPA (SPRA) are considered to manifest an aggressive disease course compared with seronegative RA patients (SNRA). However, the relationship between seropositivity and measures of disease severity other than radiologic outcome is disputed.

Objectives: In this study, we sought to compare the clinical presentations and treatment outcomes of SNRA and SPRA patients.

Methods: A total of 241 patients diagnosed with DMARD-naive RA under either 1987 American College of Rheumatology (ACR) criteria or 2010 ACR/European League Against Rheumatism (EULAR) criteria were identified (40 with SNRA and 201 with SPRA). We investigated the disease activity measures including ESR, CRP, patient VAS, 28 tender/swollen joint count (28 TJC, 28 SJC) and DAS28 as well as radiologic outcomes at baseline, 1 and 2 years after conventional treatment with DMARD.

Results: Age, sex and disease duration were similar between SNRA and SPRA. However, the baseline 28 TJC $(4.7 \pm 2.9$ vs. $3.3 \pm 2.7, p=0.004), 28$ SJC $(4.3 \pm 3.0$ vs. $2.9 \pm 2.3, p=0.001)$ and DAS28 (5.1 \pm 1.0 vs. $4.7 \pm 1.0, p=0.043)$ components were significantly higher in SNRA than in SPRA. Over 2 years of similar treatment with DMARDs, all disease activity measures significantly improved in both groups. Notably, $\triangle \mathrm{DAS} 28$ from baseline at 1 year was significantly greater in SNRA compared with SPRA $(-2.9 \pm 1.2$ vs. $-2.2 \pm 1.8, p=0.002)$. Radiologic outcomes at baseline and at 1 - or 2 year follow-up were similar between the 2 groups

Conclusions: SNRA patients manifested more active disease at baseline, but showed a better response to treatment compared with SPRA. SNRA does not appear to be a benign subtype of RA

Disclosure of Interest: None declared

DOI: 10.1136/annrheumdis-2018-eular.3373

\section{AB0260 ASSOCIATION BETWEEN ANTI-CITRULLINATED PROTEIN ANTIBODY STATUS, EROSIVE DISEASE AND HEALTHCARE RESOURCE UTILISATION IN PATIENTS WITH RA}

L.R. Harrold ${ }^{1}$, L. Guo ${ }^{2}$, S.E. Connolly ${ }^{3}$, E. Alemao ${ }^{3}$, S. Rebello' ${ }^{2}$, Y. Shan ${ }^{2}$, J. M. Kremer ${ }^{4} .{ }^{1}$ University of Massachusetts Medical School, Worcester, MA; ${ }^{2}$ Corrona LLC, Waltham; ${ }^{3}$ Bristol-Myers Squibb, Princeton; ${ }^{4}$ Albany Medical College and The Center for Rheumatology, Albany, USA

Background: Anti-citrullinated protein antibody (ACPA) is a highly specific biomarker for RA ${ }^{1}$ and ACPA-seropositive patients have a tendency toward severe erosive disease and more rapid disease progression. ${ }^{2-4}$ Little is known regarding the impact of poor prognostic factors, such as ACPA and erosive disease, on healthcare resource utilisation (HCRU).

Objectives: To characterise the rate of HCRU between anti-cyclic citrullinated peptide (anti-CCP; a surrogate of ACPA) positive (+) patients with or without erosions who initiated biologic (b)DMARD treatment.

Methods: This analysis included patients aged $\geq 18$ years, who were enrolled in a large sequential RA registry (October 2001-August 2017) and who had known erosions, as measured by radiography, and anti-CCP +status at or prior to bDMARD initiation visit and a 12 month ( \pm 3 months) follow-up visit. Anti-CCP +was defined as $\geq 20 \mathrm{U} / \mathrm{mL}$. Rates of HCRU, including all-cause hospitalizations, all joint surgeries (total and partial; all sites), radiographic procedures and use of assistive devices, were estimated over 12 months of follow-up from the bDMARD initiation visit in anti-CCP + patients with or without erosions. Rates of HCRU per 100 patient-years and risk ratios, adjusted by baseline age, were estimated with 95\% Cl using a Poisson regression model.

Results: A total of 2047 anti-CCP +patients were included in this analysis, 868 with and 1179 without erosions. At biologic initiation visit, mean (SD) age was 58.9 (12.5) and 55.9 (12.5) years and disease duration was 11.7 (10.1) and 6.4 (7.5) years, respectively, in anti-CCP + patients with and without erosions. Over 12 months of follow-up, the rates of HCRU were higher among anti-CCP +patients with versus those without erosions at baseline bDMARD initiation visit (table 1). Conclusions: ACPA seropositivity with erosive disease predicts high utilisation of healthcare resources, suggesting that early therapeutic intervention may be warranted in anti-CCP + patients to achieve better disease control and reduce the complications from RA.

Abstract AB0260 - Table 1. Age-Adjusted Rates (95\%Cl) of HCRU and Adjusted Risk Ratios in Anti-CCP+ Patients With RA With and Without Erosions

\begin{tabular}{|c|c|c|c|}
\hline & \multicolumn{2}{|c|}{ Age-adjusted rate $(95 \% \mathrm{Cl})^{\star \dagger}$} & \multirow{2}{*}{$\begin{array}{c}\text { Adjusted risk ratio } \\
(95 \% \mathrm{Cl})^{\star \dagger} \\
\text { Anti-CCP+/erosions vs } \\
\text { anti-CCP+/no erosions }\end{array}$} \\
\hline & $\begin{array}{l}\text { Anti-CCP+and no } \\
\text { erosions }(n=1179)\end{array}$ & $\begin{array}{c}\text { Anti-CCP } \\
\text { +and erosions } \\
(n=868)\end{array}$ & \\
\hline $\begin{array}{l}\text { Hospitalisation, } \\
\text { all cause }\end{array}$ & $9.44(7.77-11.37)$ & $\begin{array}{c}15.21(12.72- \\
18.05)\end{array}$ & $1.47(1.14-1.90)$ \\
\hline $\begin{array}{l}\text { Joint surgery } \\
\text { visits, all sites }\end{array}$ & $3.74(2.72-5.02)$ & $5.34(3.91-7.12)$ & $1.31(0.86-1.98)$ \\
\hline $\begin{array}{l}\text { Radiography, } \\
\text { all cause }\end{array}$ & $18.12(15.77-20.72)$ & $\begin{array}{c}22.18(19.14- \\
25.56)\end{array}$ & $1.25(1.03-1.53)$ \\
\hline $\begin{array}{l}\text { Assistive } \\
\text { devices }\end{array}$ & $60.65(56.28-65.27)$ & $\begin{array}{c}73.03(67.44- \\
78.97)\end{array}$ & $1.12(1.00-1.25)$ \\
\hline
\end{tabular}

${ }^{*}$ Rates per 100 patient-years with $95 \% \mathrm{Cl}$ based on Poisson distributed counts

${ }^{\dagger}$ Adjusted for baseline age

Reference group: anti-CCP +and erosions

\section{REFERENCES}

[1] Scott DL, et al. Lancet 2010;376:1094-108.

[2] van der Helm-van Mil AH, et al. Arthritis Res Ther 2005;7:R949-58.

[3] Hecht C, et al. Ann Rheum Dis 2015;74:2151-6.

[4] Harrold LH, et al. Arthritis Rheumatol 2017:69(S10):499.

Disclosure of Interest: L. Harrold Shareholder of: Corrona, LLC, Grant/research support from: Pfizer, Consultant for: Roche, Bristol-Myers Squibb, L. Guo: None declared, S. Connolly Shareholder of: Bristol-Myers Squibb, Employee of: BristolMyers Squibb, E. Alemao Shareholder of: Bristol-Myers Squibb, Employee of: Bristol-Myers Squibb, S. Rebello Employee of: Corrona, LLC, Y. Shan Employee of: Corrona, LLC, J. Kremer Shareholder of: Corrona, LLC, Grant/research support from: AbbVie, Bristol-Myers Squibb, Genentech, Lilly, Novartis, Pfizer Employee of: Corrona, LLC

DOI: 10.1136/annrheumdis-2018-eular.1582

\section{AB0261 ONGOING GOOD RESPONSE WITH BIOLOGICS. DATA FROM THE AUSTRIAN BIORG REGISTRY}

M. Herold ${ }^{1,2}$, G. Eichbauer-Sturm ${ }^{3}$, T. Nothnagl ${ }^{4}$, R. Puchner ${ }^{5}$, B. Rintelen ${ }^{4}$, P. Spellitz ${ }^{6}$, B.F. Leeb ${ }^{4}$, on behalf of BioReg Austria. ${ }^{1}$ Department of Internal Medicine II, Innsbruck Medical University, Innsbruck, ${ }^{2}$ BioReg Austria, Vienna; ${ }^{3}$ Rheumatologist in private practice, Linz; ${ }^{4} 2 n d$ Department of Internal Medicine Lower Austria State Hospital, Stockerau; ${ }^{5}$ Rheumatologist in private practice, Wels;

${ }^{6}$ Rheumazentrum Wien-Oberlaa, Vienna, Austria

Background: The goal for the treatment of rheumatoid arthritis (RA) should be remission or at last low disease activity. Using data of the Austrian biologic registry we evaluated disease activity in patients with RA and treated with biologics for more than six years.

Objectives: The aim of this evaluation was to elucidate long term disease activity in patients with RA who are treated with a biologic. We checked data at baseline and at control-visits every six months after inclusion in BioReg.

Methods: Data were extracted from the Austrian BioReg registry (http://www.bioreg.at) which was initiated in 2009 to document patients treated with one of the biologics approved in Austria. Patients with ongoing biologic therapy as well as biologic-naive patients starting biologic therapy can be included (baseline, BL). Further documentation is recommended about every 6 months (V2, V2 up to V12). Until September 2017, 2132 patients (1157 RA, 497 SpA, 401 PsA, 77 other diseases) have been documented.

Estimation of disease activity was done using DAS-28, RADAI-5, HAQ as well as ESR and CRP.

Results: DAS-28 (median values of BL; V2; V4; V10;V12) of our patients with RA are 3,$30 ; 2,51 ; 2,33 ; 2,49 ; 2,58$, the respective RADAI-5 values are 3,$20 ; 2,20$; 2,$00 ; 2.00 ; 2,40$ and values of $H A Q$ are 0,$75 ; 0,50 ; 0,50 ; 0,50 ; 0,63$. Median values of inflammation's laboratory markers (ESR in $\mathrm{mm} / 1 \mathrm{st}$ hour and CRP in $\mathrm{mg} / \mathrm{l}$ ) were always within or close to the normal range (ESR and CRP in RA 15; 12; 11,5; 13,$5 ; 11$ and 2,$1 ; 2,0 ; 2,0 ; 2,4 ; 3,0$

Conclusions: Our data confirm the efficiency of therapy with a biologic. During 6 years of continuous treatment more than half of the patients with RA are continuously in remission or low disease activity with a DAS-28 below 2,6, RADAI-5 equal or below to 2,40 and normal values of ESR and CRP. 
Acknowledgements: BIOREG is supported by an unlimited industrial grant Disclosure of Interest: None declared DOI: 10.1136/annrheumdis-2018-eular.7053

\section{AB0262 2 SEARCHING PREDICTORS OF ABATACEPT EFFICACY IN PATIENTS WITH RHEUMATOID ARTHRITIS}

M. Borisova ${ }^{1}$, G. Lukina ${ }^{1,2}$, Y. Sigidin Y.A ${ }^{1}$, E. Aronova ${ }^{1}$, E. Luchihina ${ }^{3}$, D. Karateev ${ }^{3}$, A. Novikov $^{2}$, E. Alexandrova ${ }^{2}$, M. Cherkasova $^{1}$, S. Glukhova ${ }^{1}$, E. Nasonov ${ }^{1} .{ }^{1}$ V.A. Nasonova Research Institute of Rheumatology; ${ }^{2}$ A.S. Loginov Moscow Clinical Scientific Center, ${ }^{3}$ Moscow Regional Research and Clinical Institute ("MONIKI"), Moscow, Russian Federation

Background: Biologics have revolutionised the treatment of rheumatoid arthritis (RA). Several types of biologics are used in clinical practice, one of them is the blocker of $T$ cells co-stimulation - abatacept (ABA). The search for predictors of biologics efficacy is an important issue in current rheumatology practice.

Objectives: To identify predictors of ABA efficacy based on the analysis of various serum biomarkers changes.

Methods: 44 RA pts with a history of previous DMARDs and biologics failures and 16 healthy donors as controls were included in the study. The majority of pts were females, RF-positive - 80\%, anti-CCP-positive - 79,5\%, mean age 49.6 \pm 13.9 years, median disease duration $2^{1,4 ; 3}$ years, with high RA activity (mean $\mathrm{DAS} 28=5,2 \pm 0,8)$. Enzyme-linked immunoassay was used to measure serum concentrations of biomarkers IL-1 $\beta$, IL-6, IL-17AF, TNF- $\alpha$, VEGF-A, IP-10, YKL-40, MMP3 at baseline and after 6 months of ABA therapy. Disease activity was assessed every 3 months using DAS28. ABA were administered IV according to standard schedule.

Results: RA pts had significantly increased levels of IL-6 $(2.4[1.1-6,4]$ vs 0.7 $[0,62-1,0] \mathrm{pg} / \mathrm{ml}, \mathrm{p}=0,0002)$, YKL-40 (97 $\left.7^{68,4-97,9} \mathrm{vs} 64^{52,4-107,5} \mathrm{pg} / \mathrm{ml}, \mathrm{p}=0.03\right)$, and IP-10 (21 $1^{12,9-49,8}$ vs $\left.14^{9,2-15,2} \mathrm{pg} / \mathrm{ml}, \mathrm{p}=0.005\right)$ compared to the control group. By the 6-th month ABA significantly reduced the levels of IL-6 up to 1.29 [0,92 ,2] $\mathrm{pg} / \mathrm{ml}, \mathrm{p}=0.0006$ and IP-10 - to $14^{7,5-28} \mathrm{pg} / \mathrm{ml}, \mathrm{p}=0.007$, as well as MMP3 and $R F$ from $30.1^{13-82}$ to $10[7.4-55] \mathrm{pg} / \mathrm{ml}, \mathrm{p}=0.0003$ ) and from 218 [9.6-187] to 159 [9.7-155] pg/ml, $p=0.02)$, respectively. There was a significant correlation between the decrease of IL-6 $(r=0.5)$ and IP-10 $(r=0,32)$ levels and decrease of DAS28 scores $(p<0.05)$. A trend to a more pronounced reduction in disease activity was identified in anti-CCP-positive and anti-MCV-positive pts. By EULAR criteria the percentage of no-responders among anti-CCP-negative and anti-MCVnegative was almost two times higher as compared to antibodies-positive pts, i.e. $27.2 \%$ vs $16 \%$ and $26.7 \%$ vs. $14.8 \%$, respectively, although the difference failed to reach statistical significance. However, by 6 months the percentage of pts with high disease activity among anti-MCV-negative pts were significantly higher than among anti-MCV-positive ( $20 \%$ and $0 \%, p=0.03$, respectively). Higher baseline IL-6 $(p=0.03)$ and $Y K L-40(p=0.02)$ levels were registered among non-responders to ABA therapy.

Conclusions: ABA therapy led to a significant reduction in concentrations of proinflammatory IL- 6 and IP-10 cytokines, as well as of MMP3 and RF. The decrease of IL- 6 and IP-10 levels significantly correlated with the decrease of RA activity. There was a trend towards more pronounced reduction of disease activity in antiCCP-positive and anti-MCV-positive pts. High baseline IL-6 and YKL-40 levels were significantly more frequently registered among non-responders. Therefore, anti-MCV-negativity, high baseline levels of IL-6 and YKL-40 could be used as predictors of insufficient ABA efficacy in this category of pts. A small sample of pts is the major limitation of this study, requiring future studies.

Disclosure of Interest: None declared

DOI: 10.1136/annrheumdis-2018-eular.3482

\section{AB0263 1 TREND IN TUBERCULOSIS INFECTION INCIDENCE IN RHEUMATOID ARTHRITIS IN SPAIN: AN OBSERVATIONAL COHORT STUDY (1999-2015) (TREND-AR STUDY)}

M. Espinosa Malpartida ${ }^{1}$, C. Barbadillo ${ }^{2}$, H. Godoy ${ }^{2}$, M. Peña ${ }^{3}$, C. Macía ${ }^{4}$ A. García-Vadillo ${ }^{5}$, J.L. More ${ }^{6}$, M. Fernánde Prada ${ }^{7}$, M. Galindo ${ }^{8}$, C. MartínezPrada $^{9}$, C. Morado ${ }^{9}$, Á. Herranz ${ }^{10}$, V. Villaverde ${ }^{11}$, N. Crespi ${ }^{12}$, O. Guzón ${ }^{3}$ E. Perez Fernandez ${ }^{3}$, J. Quirós ${ }^{3}$, R. Mazzucchelli ${ }^{3}$, on behalf of TREND-AR. ${ }^{1}$ Rheumatology, Hospital Universitario Puerta de Hierro Majadahonda; ${ }^{2} \mathrm{H} . \mathrm{U}$. Puerta de Hierro Majadahonda; ${ }^{3}$ H. U. Fundación Alcorcón; ${ }^{4} H$. U. Severo Ochoa; ${ }^{5} \mathrm{HU}$ La Princesa; ${ }^{6} \mathrm{HU}$ Ramón y Cajar, Madrid; ${ }^{7} \mathrm{H}$. U. Guadalajara, Guadalajara; ${ }^{8} \mathrm{HU} 12$ de Octubre; ${ }^{9} \mathrm{HU}$ Clínico San Carlos; ${ }^{10} \mathrm{H}$. U. del Henares; ${ }^{11} \mathrm{HU}$ Móstoles; ${ }^{12}$ CS La Rivota, Madrid, Spain

Background: There have been important changes in the management of rheumatoid arthritis (RA) in the last 20 years, due to the incorporation of new drugs. An increase in the incidence of tuberculosis infection (TB) has been observed because of reactivation of latent TB with the use of new treatments. Adequate prevention measures have been implemented.

Objectives: To analyse the incidence and trend of hospital admissions for TB in patients with RA in Spain during the period between 1999 and 2015

Methods: This is a retrospective population based study. We analysed a national administrative database that includes a Minimum Basic Data Set (MBDS) of hospital admissions of patients with RA. Period: 1999 to 2015. The TB cases were identified by the presence in primary and secondary diagnosis of ICD 9 codes. The population at risk was estimated through the population census of the National Institute of Statistics, with an estimated prevalence of RA of $0.5 \%$. The crude and adjusted rates of TB were calculated. The trend was analysed using Generalised Linear Models (GLM) using the year variable as the analysis variable.

Results: Among all the admissions of patients with AR (338.343), 1209 (0.35\%) were due to TB, 665 (55\%) in women and 544 (44.9\%) in men. The mean age was 63.25 (SD 13.7). The mean of the Charlson index was 1.84 (SD 1.45), in women 1.63 (SD 1.3) and in men 2.09 (SD 1.59) $(p<0.001)$

There were a total of $94(7.8 \%)$ deaths during admission $(6.9 \%$ in women, $8.8 \%$ in men, $\mathrm{p}=0.231$ ). The TB age-adjusted rate during the study period was 42.78 100.000 inhabitants RA-year (28.2 in women and 100.74 in men). The TB ageadjusted rate in both sexes remains without significant changes between 1999 and 2015 (IRR 0.225; CI95\% 0.985-1.025). During the period 1999-2011 an increase of the incidence is observed, while in the period 2011-2015 it is observed a decrease of the same (fig 1).

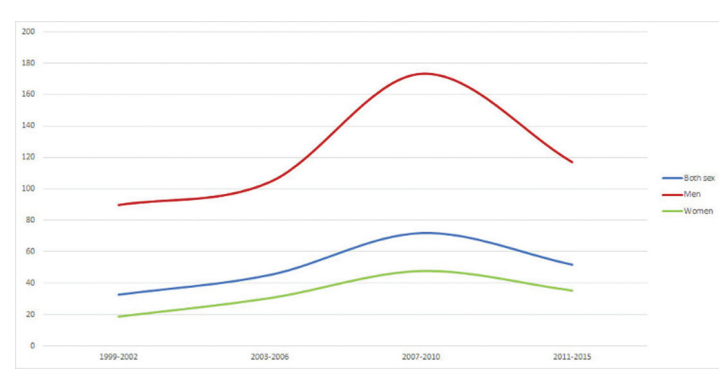

Abstract AB0263 - Figure

Conclusions: Conclusion: In Spain, in patients with RA, the income rate in relation to tuberculosis increased from 1999 to 2010 and subsequently decreased in the period from 2011 to 2015.

Disclosure of Interest: None declared

DOI: 10.1136/annrheumdis-2018-eular.4185

\section{AB0264 2 TREND IN HOSPITAL ADMISSIONS IN RHEUMATOID ARTHRITIS IN SPAIN: A NATIONAL OBSERVATIONAL COHORT STUDY (1999-2015) (TREND-AR STUDY)}

M. Espinosa Malpartida ${ }^{1}$, C. Barbadillo ${ }^{2}$, H. Godoy ${ }^{2}$, C. Martínez Prada ${ }^{3}$, V. Villaverde ${ }^{4}$, C. Morado Quinoa ${ }^{3}$, J. Quirós $^{5}$, E. Perez-Fernandez ${ }^{5}$, M. Peña ${ }^{5}$ C. Macía Villa ${ }^{6}$, A. García-Vadillo ${ }^{7}$, N. Crespi ${ }^{8}$, J.L. Morell Hita $^{9}$, M. FernándezPrada $^{10}$, M. Galindo ${ }^{11}$, O. Guzón Illescas ${ }^{5}$, Á. Herranz ${ }^{12}$, R. Mazzucchelli ${ }^{5}$, on behalf of TREND-AR. ${ }^{1}$ Rheumatology; ${ }^{2}$ H.U. Puerta de Hierro Majadahonda; ${ }^{3} \mathrm{HU}$ Clínico San Carlos; ${ }^{4} \mathrm{HU}$ Móstoles; ${ }^{5} \mathrm{H}$. U. Fundación Alcorcón; ${ }^{6} \mathrm{H}$. U. Severo Ochoa; ${ }^{7} \mathrm{HU}$ La Princesa; ${ }^{8} \mathrm{CS}$ La Rivota; ${ }^{9} \mathrm{HU}$ Ramón y Cajar, Madrid; ${ }^{10} \mathrm{H}$. U. Guadalajara, Guadalajara; ${ }^{11} \mathrm{HU} 12$ de Octubre: ${ }^{12} \mathrm{H}$. U. del Henares, Madrid, Spain

Background: There have been significant changes in the management of rheu matoid arthritis (RA) during the past 20 years. The potential impact of these strategies on hospitalisation trend is unknown.

Objectives: To analyse the incidence and trend of hospital admissions in patients with RA in Spain from 1999 to 2015.

Methods: This is a population based study. We analysed a national administrative database that includes a Minimum Basic Data Set (MBDS) of hospital admissions of patients with RA during the period 1999-2015.

The admission cases in patients with RA were identified by the presence in primary and secondary diagnosis of the ICD9 codes (714.0-714.9). The population at risk was estimated through the population census of the National Institute of Statistics, with an estimated prevalence for RA of $0.5 \%$, with crudes and adjusted admission rates being calculated. The trend was analysed using Generalised Linear Models (GLM).

Results: There were a total of 338343 hospital admissions in RA patients during the study period, accounting for a total of 176097 patients (1 17985 women and 58112 men). The mean age at admission was 68 years (67.8 in women and 68.5 